\title{
IMPORTANCE OF PHILOSOPHY IN THE CONDUCT OF EDUCATIONAL RESEARCH
}

\author{
Richard Pring \\ Department of Education, University of Oxford
}

\begin{abstract}
Educational questions, whether in policy or in practice and thus in educational research, make assumptions which are philosophical in nature - in values, theory of knowledge, philosophy of mind, social philosophy and so on. The paper illustrates this through several examples of educational research, showing how, in the absence of philosophical questioning, the intelligence is often bewitched by the misuse of language, thereby invalidating so-called educational research.
\end{abstract}

\section{Introduction}

What is educational research? There are three sorts of answers to this question.

The first answer points to the sort of research evidence which helps policy makers and practitioners to make justified decisions in the many different choices and activities which are covered by the title 'education'. For example, should we select the brighter students at age 11 to a more academic school? Well, that depends on the empirical evidence as to whether or not separate schooling helps the brighter students to achieve more academically. It also depends (something often forgotten) on the effect such a decision has upon the welfare and attainments of those not selected. These kinds of research would include the concepts, theories and facts from such disciplines as sociology, psychology, history, anthropology, and comparative studies. And there are many kinds of study which would offer evidence - it all depends on the questions being asked.

The second sort of answer is one that arises from puzzlement about the meaning of the words which are being used - often without any awareness of the grounds for puzzlement. Here one might ask what it means to say someone is intelligent. Are there different ways in which one might conceptualise intelligence so that someone might be intelligent at some things and not at others? If that is the case, than it makes little sense to divide human beings into 'intelligent' and 'not intelligent'.

The third sort of answer depends on what you mean by educational research. Why educationally should we find the psychological research on intelligence interesting? There is a lot of disagreement about what counts as an educated person, and some interesting sociological research might seem educationally relevant to some educational researchers, and irrelevant to others

The second and third questions are essentially philosophical. They are rarely asked in courses and in the conduct of educational research. That is a pity, because it explains why so much so-called educational research is not educational at all. Therefore this paper concentrates on questions 2 and 3 , but with an extension in the final part into different areas which have traditionally been explored by philosophers.

\section{It All Depends on What You Mean.}

The philosopher Wittgenstein declared his main intention in Philosophical Investigations 'to teach you to pass from a piece of disguised nonsense to something that is patent nonsense' (Wittgenstein, 1953). And there is a lot of 'disguised nonsense' which bewitches the intelligence by the misuse of language. In pursuing this particular meaning of 'philosophical investigation', and its relevance to educational studies and research, I shall give three examples:

\section{Skills}

Let us take the example of the perceived need in most countries to increase the number of skilled workforce. A lot of research is undertaken to find out what skills are needed, how many people have them and what we need to do to train more people to obtain them. In Britain there was the Leitch Report (2006) which stated that only 600,000 jobs in 2020 would require no skills, as opposed to the seven million today. Other research contradicts this;

${ }^{1}$ Correspondence can be directed to: richard.pring@education.ox.ac.uk 


\section{RICHARD PRING}

there will remain the seven million jobs requiring workers without skills. Who is right? What sort of research would show how many skilled workers there are and how many more are needed for training?

The question is posed as though it is open to empirical research. But it is in part, if not mainly, a conceptual issue. What is a 'skill'? And, given there are many different kinds and complexities of skill, how can they be added up to get the number 600,000 ? Is 'street cleaning' a skill (some streets are cleaned more effectively than others). If so, is it one or several skills (for example, using a brush nimbly and quickly, and picking up the dirt without spilling it), and how quickly can each component skill be learnt? Are street cleaners included in the overall number of skilled jobs to be trained for?

The fuzziness of the word 'skill' is not acknowledged in the research which profoundly affects policy and investment. One needs constantly to ask the question: 'What do you mean?'

\section{Standards}

Or take for example, the need to raise standards, rendered even more sharply by international comparisons of the OECD's PISA evaluations (Programme of International Student Assessment) - a most extensive and thorough piece of research which sparks soul-searching in many countries (including Britain) which find themselves further down the league table than they feel they ought to be.

But what do we mean by 'standards' - and what could be meant by such standards going up or down? First, there is something confusing about standards themselves going up or down. Standards are the benchmarks against which performance is judged to be good or bad, elegant or crude, intelligent or stupid. It is not the standard which goes up or down, but the performance which is assessed according to the standard. It is a further question as to whether the selected standards are appropriate ones. And one might ask, too, whether the adopted standards relate in content or difficulty to previous standards with which they are being compared. But for standards themselves to go up or down there would be required some reference to higher standards against which the lower standards are reckoned to be inadequate - and so on ad infinitum

This confusion over the meaning of 'standard' messes up a lot of policy - and thereby practice. One decides whether or not a learner's performance (and by extension the performance of the school) 'comes up to standard' by the 'performances', and hence the need for 'performance indicators'. These are increasingly spelled out in great detail such that standards can be measured - and a lot of research is dedicated to this. But then the 'performances' become the 'standards'. They are equated. Therefore it is wise for the teacher, in demonstrating improving standards, to 'teach to the standards' - to teach how to perform in particular circumstances. More relevant words, reflecting the practical reality, would be 'coaching' or 'training'. But are the learners demonstrating a higher standard in the educational context?

First, one needs to ask why this is educational - and thus why the PISA investigations, for instance, constitute educational research (but this will be postponed to the next section).

Second, however, is there not a logical confusion in equating aims (educational or otherwise) with indicators? A philosophical move is to work through concrete examples. Let us, therefore, take the example of 'happiness' as an educational aim. We are increasingly being told that an educational aim is to make young people happy - having a sense of fulfillment. A miserable child is likely to be discouraged from learning. One performance indicator of happiness is the amount of smiling and laughing which is shown. Therefore, in advance of the visit by the Inspector of Happiness, the teacher trains the children to smile when indicated to do so. The Inspector of Happiness arrives. Every time he tells a joke, all the children laugh or smile. He is impressed, and gives the school a top grade for 'happiness education'. The school goes to the top of the 'happiness league'. The only trouble is that the children are thoroughly miserable. There has been a logical confusion between 'performance indicators', on the one hand, and, on the other, that which they are supposed to be indicating.

Once again, so-called educational research is confounded by a failure to ask the question: 'What do you mean?'

\section{Disciplines}

Yet a further example arises from the recent book on the 'disciplines' of education by Furlong and Lawn (2011) - a reflection back to the 1960s when, to give educational studies greater academic respectability, there was the establishment in university education departments of the 'foundation disciplines'. These were the Philosophy, the Sociology, the Psychology and the History of Education. What made them 'disciplines' were the distinctive concepts which they brought to bear upon educational problems, the distinctive ways of testing the truth of what was claimed, and the distinctive modes of enquiry. Educational studies was not itself a discipline, but rather a collection of these other disciplines. The result of such a way of conceiving things was a downgrading of the teachers' own professional thinking and judgment - a deferring of professional judgment to those from the heights of the 'isms'.

However, if we were not quite so liberal with nouns, perhaps we would not 'people the world with so many objects' which such nouns seem to pick out and name. If instead of the 'disciplines of education', we spoke of 
'disciplined thinking' about education, then we make room for the centrality of teachers' thinking about education. In so doing, the teachers will draw upon the 'bodies of knowledge' under the title of sociology or psychology (distinguished by their own distinctive theoretical perspectives), but these will be sociology or psychology of education only in so far as they are seen to be relevant to educational questions raised by teachers or policy makers. There would be no such thing as the discipline of sociology of education' or of 'psychology of education'.

It is partly because of this more philosophical questioning that there has emerged within the teaching profession the powerful tradition of 'action research' - research which cannot divorce the disciplined thinking about education from professional insights and ethical deliberations, though inevitably drawing upon, where relevant, the knowledge and understanding afforded by sociology or psychology.

\section{Interim Conclusion}

So far, I have argued for and illustrated the humble but enabling role of philosophical thinking in asking 'what do you mean?' where, though often unrecognised, language is not as clear as it needs to be in order to embark on empirical research. Moreover, such lack of clarity is not easily cleared up, because beneath it lie deeper questions with which philosophers have traditionally been concerned - about the nature of knowledge, the relation of mind to matter, the relation of society to the individual, and above all the ethical concern about what is worth while learning. To that last concern we shall now turn, bearing in mind that philosophy is in great part a quest for clarity and meaning where so often language holds us captive. Again, to quote Wittgenstein 'a picture held us captive. And we could not get outside it, for it lay in our language and language seemed to repeat it to us inexorably'.

\section{What Makes Educational Research Educational?}

Again, let me work through an example. I was invited to lead a review, funded by the Nuffield Foundation to the tune of $f 1$ million, into every aspect of education and training of 14 to 19 year olds in England and Wales (Pring, et al., 2009). This was the largest such review for 50 years. Is a review a piece of research? In one important sense it is, for it requires the careful selection of research which is seen to be relevant to the questions being asked. It requires a critical review of such research - the thoroughness with which it is carried out, the verification of the conclusions reached, the validity in relation to other research which reaches opposite conclusions. But most important for the purposes of this paper is the overall question which determines the relevance of all these different pieces of research. As in the writing of one's Ph.D., one needs to ask: what is your thesis?

What stimulated the funding of this review were educational questions about the quality and the relevance of the learning which was experienced by all young people, whether high flying academics or those with special educational needs. Such quality and relevance must necessarily include the content or subject-matter of what was taught, the assessment of that quality, the qualifications which marked the success of the learning, the approaches to teaching, the opportunities afforded for progression, the provision of learning in schools, colleges and training centres. But the resolution of these concerns required a deeper analysis of the aims of education. What gave unity to the review - and relevance (or not) to the many kinds and items of evidence - was the question: What counts as an educated 19 year-old in this day and age?

The preliminary answer to that question requires both an analysis of the meaning of 'educated' and an evaluation of those qualities which someone, who is called 'educated', should possess. Hence, we are into the realms of philosophy - namely, 'what do you mean?' and 'how do you decide what is worth learning?' Let me explain

To educate in its descriptive sense entails bringing about learning in one way or another. One speaks of a person's education as the formal arrangements through which that learning is brought about. Hence, for example, one might ask a person where he or she was educated whilst simply wanting to know where he or she had gone to school.

But it is open to someone to say that such an experience was not really educational - indeed, as Dewey argued, much so-called education is mis-educational. It leads to boredom, it closes the mind to further learning, it narrows one's vision of what is possible, it undermines the learner's confidence. In so arguing the critic is using the word 'educated' in an evaluative sense. He or she is saying that what is described as education is not education at all. The evaluative sense is logically prior to the descriptive sense.

Here then we are into the realm of ethics - namely, that form of discourse, central to philosophy, which examines and deliberates about what is worthwhile and why certain actions or states of being are more worthwhile than others.

Many answers are put forward in answer to this question for the simple reason that 'educated' implies the acquisition of qualities, understandings and aspirations which are judged to be of value and worth pursuing. They are tied to what one sees, implicitly or explicitly, to be the sort of person and the sort of society, which, through learning, one would wish to see developed. 


\section{RICHARD PRING}

Values are embodied in all that we do in seeking to educate. One can see how implicit and unexamined values shape the educational programme of young people - for example, the division between the more prestigious academic pathways for some and the vocational studies for others, the significance given to the sciences rather than to the arts (or vice versa), the focus on economically relevant skills and on the qualities of entrepreneurship, the concentration upon examination grades, the absence of practical and experiential engagement. Practices and policies, too often unquestioned, become problematic against a deeper ethical critique.

In addressing such an ethical question one needs to attend to what it means to be a person because we attribute 'education' and 'educated' to persons, not to horses or cows. What, then, is the sort of learning which we believe to be worth while for persons, as such, to undergo and achieve in? The answer to that requires some analysis of what is distinctive of being and growing as a person. And so research, if it is to be educational, must shed light on the pursuit of that sort of learning - both content and process - which enable the learners to live distinctively human lives. Perhaps the 'educational research' into standards misses the point if what is measured has little relation to the qualities associated with being educated

\section{Capacity to Think}

What first distinguishes human beings (the biological species) as persons is the capacity to think about and to make sense of the physical, social, economic and moral worlds we inhabit. That 'making sense' draws upon the concepts, modes of enquiry, explanations which we have inherited through the different traditions and disciplines of thinking. Inevitably, different young people acquire such modes of thinking at different levels of sophistication. Such traditions of thinking are what we acquire initially through family and community, but the advancement of civilisation has led to the increasing powers of such thinking and its differentiation into different forms of knowledge and experiencing. That is what the philosopher Michael Oakeshott (1972) referred to as the 'conversation between the generations of mankind' into which we initiate the next generation so that they too can appreciate and internalise 'the voices' of science, of history, of poetry, of religion. These different 'voices' are characterised by their own distinctive concepts and modes of enquiry, identified and extended by philosophical argument and analysis within the separate disciplines. One might refer to such philosophical work as part of epistemology or theory of knowledge. Of course, such 'conversations between the generations' can be conducted at a very deep level - what, presumably, goes on in university departments, and many young people will not have the ability, opportunity or motivation to go into much depth. But the capacity to think systematically about the physical, social, economic and moral worlds we inhabit is possible for all young people up to a certain level, and an aim of education (in that such differentiated thinking is part of what it means to function as a person) must be to help the learners at least to start on the rung of the ladder and to make as much progress as possible and practically necessary in order, as Dewey argued, to 'manage life intelligently'. Such progress requires identifying the key ideas that structure our thinking in its different modes and the way in which such ideas can be put across in an ever more sophisticated way (what Jerome Bruner, 1960, referred to as 'the spiral curriculum').

\section{Practical Capacities}

Secondly, however, failure in educational research to reflect upon the aims of education and what it means to be and to develop as a person has resulted in a very narrow research programme into learning and curriculum. The philosopher John Macmurray (1957) argued that western philosophy had been misled by Descartes' Cogito, ergo sum - 'I think, therefore I am'. Here is the assumption of the thinking person as a spectator of a world separate from the spectator herself, and the educated person therefore as the disinterested examiner of the physical and social worlds. But, argued Macmurray, it would be more correct to say 'I do, therefore I am' - far from being the disinterested spectator, I am practically involved in the world and my understanding of it grows through being engaged, pursuing goals at first only vaguely identified, meeting problems. It is through practical experience that we come to make sense of the material world and the personal relations which are the context of our personal development. The American philosopher turned motor mechanic, Matthew Crawford (2009), shows the problems arising from the separation of thinking from doing.

The disappearance of tools from our common education is the first step towards a wider ignorance of the world of artifacts we inhabit (Crawford, 2009, p.3).

It is here where the philosopher John Dewey argues for a very different understanding of education from what prevailed in his native America. The often declared aims of education, by failing to grasp the importance of experience and of practical capability, do not produce 'the educated person' - rather a narrowly conceived human being. Hence, 'practical capabilities' are much neglected in educational theory, practice and research - and certainly unrecognised in the research into standards. 


\section{Moral Seriousness}

Third, however, what is distinctive of being a person is the capacity to take responsibility for the direction of one's life and for making moral choices. Personal development results in a degree of 'moral seriousness' - being aware of and sensitive to the big issues which confront society - those of environmental sustainability, of racism, of unnecessary poverty and disadvantage. Such awareness and sensitivity are embodied in the dispositions to behave in particular ways in particular circumstances. Is not an aim of education to nurture the virtuous person, not just the knowledgeable person? The academically successful person, without human sensibility or appropriate dispositions, and thereby using his academic success to pursue bad ends, is 'less of a person'. Such sensibilities can be learnt through an educational process (for example, the engagement with literature) and ethos which helps shape the personality and goals thought worth pursuing. Lawrence Kohlberg, known for his research into moral development, argued that it is no good teaching how to act justly unless the school itself became a just community (Kohlberg, 1982).

\section{Sense of Community}

Finally, to be a person is to be related to other persons. No one is an island. Our capacity to talk and to think arises from our relation to others both existent and in the past. We participate in a culture and in that conversation between the generations of which Oakeshott spoke. We are members of communities and human welfare depends on the health of these communities. Again, referring to Dewey, whose book Democracy and Education put the creation of thinking and supportive communities (citizenship, if you like) as the central aim of education,

Men live in a community in virtue of the things which they have in common. What they must have

in common in order to form a community or society are aims, beliefs, aspirations, knowledge - a common understanding. (Dewey, 1916, p.4)

Not to foster community and the interpersonal respect central to community was to cut individuals off from the chief means of personal growth - that experiential learning through which one comes to understand and benefit from the different cultural standpoint of others different from oneself

\section{Interim Conclusion}

The educated person therefore is one who has developed these distinctive qualities and capacities of 'becoming a person more fully', namely, the initiation into the different forms of knowledge and understanding, into moral traditions which can so easily come to be neglected, into practices of doing and making, and into civic and public traditions of service.

Of course within such generalities there will be areas of disagreement, reflecting different values placed upon different content within forms of knowledge, reflecting too different understandings of society and how it might prosper. But the virtues to be fostered through the conduct of educational research - the intellectual virtues of openness to argument, of honesty in presenting evidence, of humility in the face contradiction, and the moral virtues of respect for other people and of due consideration to others' views howsoever mistaken - should enable each to be enriched by such differences.

Where one stands on these essentially ethical issues embodied within the aims of education affects profoundly what the shape and provision education should be. And yet policies and practices are pursued, and research conducted, as thought the whole matter is ethically neutral.

\section{Research Based Teaching}

The separation of theory from practice (the Cartesian spectator view of thinking, referred to above) has led to a research tradition in education dominated by the theoretical work of sociologists, psychologists and philosophers, disconnected from the practice of education as that is carried out by teachers. It is the teachers, by and large, who educate - who need to think therefore what counts as an educated person and how the knowledge which is produced by the theoreticians might be integrated into their (the teachers') practical and experiential knowledge in the pursuit of their educational aims. In that respect, the teachers have to be the researchers - not the deliverers of other people's research.

Such a tradition of what is referred to as 'action research' puts the teacher at the centre. But there are two aspects of this which are of philosophical importance. 


\section{RICHARD PRING}

\section{The Concept of Teaching}

First, we need to ask what it means to teach. What seems to be a straightforward question turns out not to be so. 'To teach' has both a direct and an indirect object. One teaches something to somebody. Teaching is the attempt to bring about the learning of something (for example, the concept of osmosis in biology or of simultaneous equations in mathematics) in someone else. But such an attempt logically requires two things: first, the logically correct exposition of the concept (or formula or event) which one wishes the learner to understand, and, second, the connection between that concept (e.g. osmosis) and the present understandings and level of ability of the learner. The university lecturer who delivers his notes to an audience of undergraduates without any consideration of their current state of knowledge or their motivation is lecturing but not teaching

\section{Teacher as Educator}

This is a purely conceptual point about the linguistic use of the word 'teaching'. But in different cultural contexts 'teaching' takes on an added meaning. Allan Bloom, in The Closing of the American Mind, concerned about the impoverishment of education in the American high school and higher education, seeks to re-instate the teacher as the custodian of that cultural tradition whereby our very humanity is enhanced. The teacher

...is, willy-nilly, guided by the awareness, or the divination, that there is a human nature, and that assisting its fulfilment is his task (Bloom, 1987).

And for Dewey $(1897$, p.32) similarly education is the fundamental method of social progress and reform', and in one extravagant moment he described the teacher as 'the true prophet and usherer in of the kingdom of God'.

Such a concept of teaching goes beyond the basic linguistic usage and sees 'the teacher' in a cultural role within society - the maintainer of a cultural tradition within which the distinctive human capabilities are preserved, passed on and enhanced.

To meet such a responsibility school teachers need to have, not only a deep understanding of those different traditions ('the different voices between the generations of mankind') but also the pedagogical skills to relate them to the modes of understanding, experiences and concerns of the learners themselves. To that end, it was seen to be necessary to

consider the role of the teacher in relation to the actual conduct of research ... problem solving research, shading into development work. (Morrell, 1967, p.22)

Morrell's vision required of the teachers an active role in curriculum development. This in turn required knowledge of the subject or practice to be taught, respect for the experiences and concerns of the learners, exploration with other teachers of pedagogy, and shared systematic enquiry into problems faced.

That 'exploration' and that 'shared systematic enquiry' constitutes the action research which enhances the professional role of the teachers. It requires, in the light of the teachers' interpretation of the aims of education, knowledge of the learner and understanding of the subject matter, the constant deliberation and testing out in the classroom of the tentative solutions to problems met. The word 'deliberation' is important, because the 'ends to be reached', broadly conceived, have to be translated into specific goals for this or that learner in this or that circumstance. The research-based teacher is formulating hypotheses and testing them out in practice. Such hypothesis formulation and testing qualifies for genuine research where it is pursued systematically, most probably in co-operation with other teachers. 'Teacher research' is extensively analysed by John Elliott (1991) in his book on action research. The important point for the sake of the present argument is that such research is essential for the intelligent and practical pursuit of learning and that, far from being an application of the findings of research in sociology, psychology and so on, it is a distinctive kind of research in which ethical questions about aims are integrated with practical proposals and empirical testing of hypotheses.

\section{Relevance of Different Kinds of Philosophical Questions}

Philosophy, as I have pointed out, puzzles away at what one means - seeing difficulties which otherwise go unrecognised - 'bewitchment of the intelligence by the use of language'. But the difficulties often lie in the failure to see how what we say and what we claim to be true introduce the problems which have always been the province of philosophers. Philosophical theses in ethics, epistemology, philosophy of mind and political philosophy permeate almost every aspect of research into educational policy, practice and research, though this is seldom recognised. It is the job of the philosopher to make explicit what is implicit in such educational thinking. 


\section{Ethics}

This has already been illustrated by showing how claims for research to be educational takes us into the realm of ethics - into deliberations about what is worth while in the development of persons. So much 'educational' research is conducted as though education is not a disputed concept - disputed either because it is used purely descriptively and ignoring the evaluative criticism of it, or because different people have a different ideas about what counts as an educated person. Such disputes have profound effect upon research into learning, both the subject-matter that should be learnt and the process through which it is learnt. If one emphasises one aspect of being a person, namely, the capacity to think systematically and deeply about the arts and the sciences, then one will associate 'educated' with the sort of academic elite and the inhabitants of a distinctive culture, and exclude the rest as uneducated and even ineducable. But if one recognises the achievements of practical learning, the rigorous standards whereby practical people engage with the physical and social environments, then one widens the notion of an educated person - and indeed questions the education standards by which academic success is so elevated.

\section{Epistemology or Theory of Knowledge}

Research into educational practice and policy instantly raises questions about the nature of knowledge in general and its different forms in particular. Becoming more knowledgeable is clearly important for personal development. But what is this 'knowledge' to be acquired? A traditional analysis is that it is a (a) a belief, (b) which is true, and (c) whose claim to truth can be justified. One might have true beliefs, for example, without any good grounds for believing that they are true - and yet pass for 'knowledge' in examinations by which learners and their schools are judged. But here lies the problem, for different sorts of belief have different sorts of justification. A true belief in science is thereby logically different from a true belief in history. And many people would question whether it makes sense to speak of 'true beliefs' in morals, politics and religion.

If that is the case, can we be justified in teaching these beliefs as if they counted as knowledge? Furthermore, in teaching scientific or historical knowledge as such one would need to teach the underlying justification as to why this is knowledge - the basis of the knowledge claims. To teach science is to enable young people to think and to practise scientifically, to have a grasp of scientific method, and to realise that scientific conclusions are always tentative and open to refinement in the light of further discoveries. One learns through criticism and correction. In teaching, there needs to be room as much for doubt as for certainty.

This applies equally to educational research. Governments talk of evidence-based policy. But too often evidence is confused with proof, and proof is too often seen as leading to certainty. But research can produce no certainty, and evidence can range from the strong to the weak. Decisions have to be made after the weighing of evidence, knowing that there may well be further evidence to show that one got it wrong. Conclusions have to be tentative, drawing on the best evidence which is available at the time.

\section{Philosophy of Mind}

Philosophy has traditionally pursued the difficulties which arise in relating the physical world to the mental world. Is a person two substances - that of the mind (where 'intelligence' resides) and that of the body (the observable behaviour of which is guided by the intelligence) - or one substance? If two (mind and body), how does the one relate to or affect the other? Research into intelligence (see works by Cyril Burt, for instance), affected profoundly the lives and fortunes of countless children - whether or not 'intelligence' was innate, thereby supporting a segregation of intelligent from unintelligent children on entry to secondary education. But let us shift from using nouns to using adverbs. Can a person be enabled to think and to act more intelligently? When you examine this question more closely, you might want to know in what context one is asking about intelligent thinking and actions. The philosopher may be unable to act intelligently when mending his electrics, whereas the electrician could not intelligently dispute the philosopher's analysis of 'intelligence'. One can see why, in recognising the diverse ways and contexts in which one might be considered to be acting intelligently, the notion of an innate 'intelligence', basically unaffected by nurture and learning (and the object of much 'educational' research), becomes increasingly unintelligible as a reason for segregating learners.

\section{Social and Political Philosophy}

Central to much educational research is the understanding of other societies, starkly so when researchers from the World Bank, UNESCO or other international agencies (for example, McKinsey's) conduct research into different countries, make comparisons, conclude what is wrong and make proposals for improvement. But how can the researcher understand a society or culture very different from his or her own - inhabiting a very different cultural and moral understanding of society, relationships and personal development? But the problems here are not 


\section{RICHARD PRING}

confined to comparative research into different countries. Research into social groups within the 'same society' equally raise these difficulties - for instance, the middle-class and educated male researcher researching the cultural context of the working-class, illiterate, female members of a gangland culture. The 'idea of a social science' (see Winch, 1958) cuts deeply into the nature and validity of educational research.

\section{Conclusion}

Educational research is seen in essence to be empirical and thus located in such theoretical disciplines as sociology, psychology, politics, philosophy. Education departments in universities, therefore, contain researchers in these areas who apply heir knowledge to educational policy and practice. The argument of this paper, however, is that much of that research, though to be drawn upon where relevant by policy makers and practitioners, is to be criticised for its lack of philosophical thinking in two important respects.

The first is that what often seem to be straightforward empirical matters are, upon investigation, not so. It all depends on what you mean.

The second is that 'what you mean' in education is inseparable from wider ethical issues about what counts as an educated person. Following from this is the need to reconsider what we mean by 'educational thinking' and thus what is distinctively educational research, something engaged in not by disinterested spectators but by the teachers who are striving to educate the next generation.

\section{References}

Bloom, A. (1987). The closing of the American mind. New York: Simon and Schuster.

Bruner, J. (1960). The process of education. Cambridge, MA: Harvard University Press.

Crawford, M. (Ed.) (2009). The case for working with your hands - Or why office work is bad for us and fixing things feels good. London: Penguin Books Ltd.

Dewey, J. (1897). My pedagogic creed. The School Journal, 5.

Dewey, J. (1916). Democracy and education. N.Y.: The Free Press.

Elliott, J. (1991). Action Research for educational change. Milton Keynes: Open University Press.

Furlong, J. \& Lawn, M. (2011). The disciplines of education. London: Routledge.

Kohlberg, L., (1982). Recent work in moral education. In L.O. Ward, (Ed.) The ethical dimension of the school curriculum. Swansea: The Pineridge Press.

Leitch, S. (2006). Prosperity for all in the global economy - World class skills. London: Home Office.

Macmurray, J. (1957). The self as agent. London: Faber and Faber.

Morrell, D. (1967). Education and change. London: College of Preceptors.

Oakeshott, M. (1972). Education: The engagement and its frustration. In T. Fuller (Ed.). Michael Oakeshott and education. London: Yale University Press.

Pring, R., et al. (2009). Education for All: The future of education and training for 14-19 year-olds in England and Wales. London: Routledge.

Winch, P. (1958). The idea of a social science. London: Routledge and Kegan Paul.

Wittgenstein, L. (1953). Philosophical investigations. Oxford: Blackwell. 